\title{
The Role of Spin-orbit Coupling in the
}

\section{Double-ionization Photoelectron Spectra of $X \mathrm{CN}^{2+}(X=\mathrm{Cl}, \mathrm{Br}$ and $\mathrm{I})$}

\author{
Soumitra Manna, and Sabyashachi Mishra* \\ Department of Chemistry, Indian Institute of Technology Kharagpur, Kharagpur, India \\ E-mail: mishra@chem.iitkgp.ernet.in
}

RUNNING HEADER: Photoelectron Spectra of $X_{C N}^{2+}(X=\mathrm{Cl}, \mathrm{Br}$ and I)

*To whom correspondence should be addressed 
Table S1: Optimized geometry of the excited states of $\mathrm{XCN}^{2+}$ with CASSCF level of electron correlation.

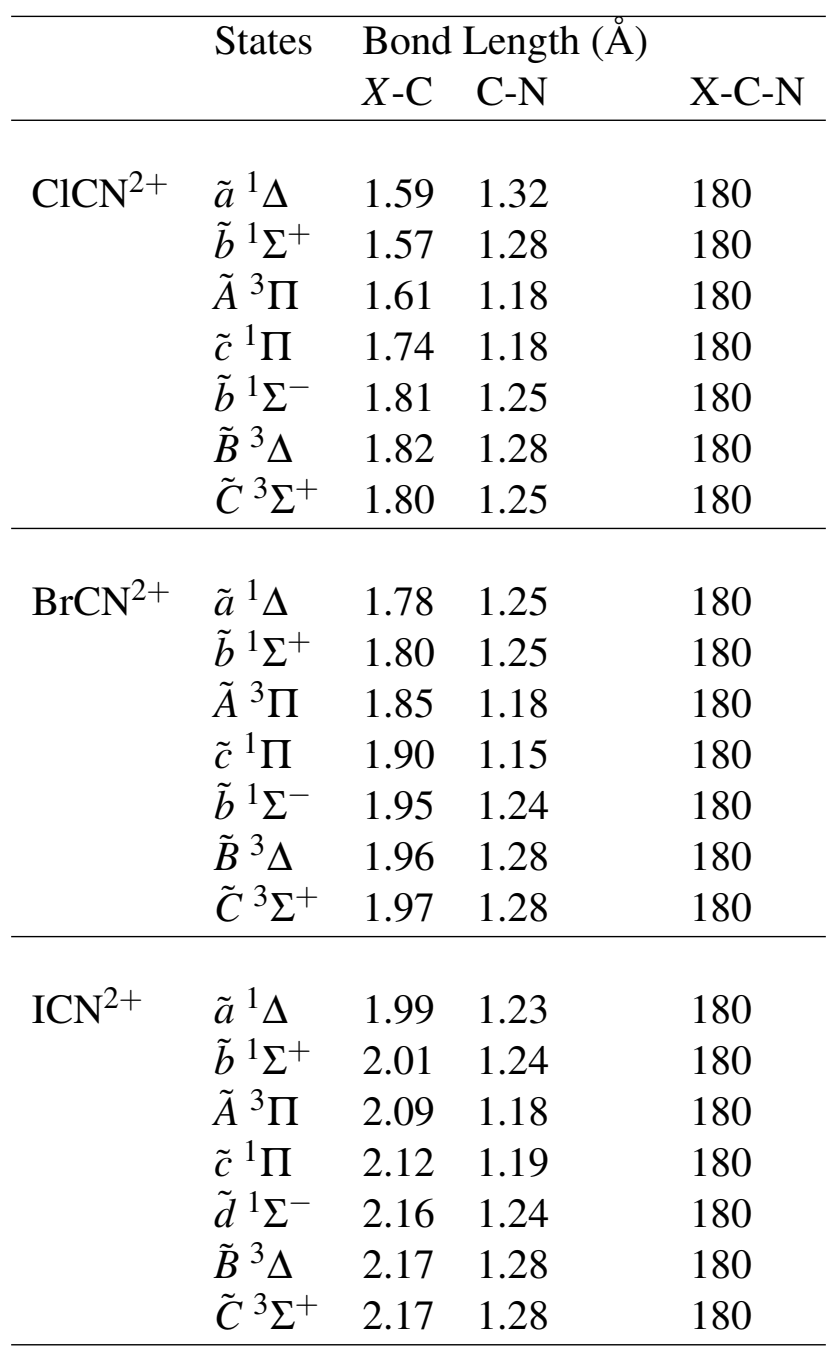

